\title{
The Monthly Effects in Chinese Gold Market
}

\author{
Ming $\mathrm{Qi}^{1} \&$ Wenyao Wang ${ }^{2}$ \\ ${ }^{1}$ School of Business Administration, China University of Petroleum (Beijing), Beijing, China \\ ${ }^{2}$ China National Gold Group Corporation, Beijing, China \\ Correspondence: Ming Qi, School of Business Administration, China University of Petroleum (Beijing), Beijing, \\ 102249, China. Tel: 86-10-8973-3793. E-mail: qiming19810114@gmail.com
}

Received: August 7, 2013

Accepted: September 5, 2013 Online Published: September 26, 2013

doi:10.5539/ijef.v5n10p141

URL: http://dx.doi.org/10.5539/ijef.v5n10p141

\begin{abstract}
In this paper, we examine the calendar effects in Chinese daily gold returns from 30 December 2002 to 05 November 2011. We find that the average gold returns appear to be higher in February, September and November than in other months. Furthermore, using the GED-GARCH $(1,1)$ approach, we find significant gold return anomalies in February, April, August, September, November and December. Most of these months occur before the public 7-day-holidays, which are called "Golden Weeks" in China. The expected strong demand before the holidays has pushed up the investment returns of gold. These findings provide convincing evidence of monthly effects in Chinese gold market. They might be of considerable importance for gold investors and traders.
\end{abstract}

Keywords: seasonal anomalies, calendar effects, gold price, Golden Weeks

\section{Introduction}

The monthly effect is one of the most frequently documented seasonal anomalies in capital markets. The returns in a specific month, e.g. January, are much higher than in other months. However, almost all previous studies have focused on the equity market. (Bouman \& Jacobsen 2002; Fountas \& Segredakis 2002; Lucey \& Zhao 2008) It appears that very little attention has been paid on the calendar effect in the commodity market. Since gold plays an important role in hedging against the economic uncertainty in the equity market, it is worthy to investigate whether the monthly effect exists in the gold market. The deregulation of Chinese domestic gold market started from 2001. With the establishment of the Shanghai Gold Exchange (SGE) in 2002, the gold demand has been growing substantially. According to the "China Gold Report" (2010) by World Gold Council (WGC), China has ranked second in gold consumption, which amounts up to a combined total of 428 tonnes, and fourth in annual gold retail investment around the world in 2009. Furthermore, the Chinese gold consumption level is expected to double in the next decade. Apart from the gold's symbolic character of wealth in Chinese conventional culture, the rising resident income and domestic inflation expectation also pushed up the gold price. For instance, the closing spot prices of AU9995 has soared from 83.52 ¥ per gram in 30 December 2002 up to $338.16 ¥$ per gram in 05 November 2012. Figure 1 illustrates the movements of daily closing prices (AU9995 and AU9999) from 2002/10/30 to 2012/11/5 in Chinese Gold market. We find in general the Gold prices keep rising. Due to the global financial crisis, the gold prices decreased in 2008. The average monthly prices of gold (AU9999) are shown in Figure 2, from which we find higher average prices occured in May, August, September and October. In spite of some strong prices in these months, there has been no previous work that involves the calendar effects in Chinese gold market. This paper aims to contribute to the debate on calendar effects by examining the month-related seasonality of gold spot prices in Chinese market. 


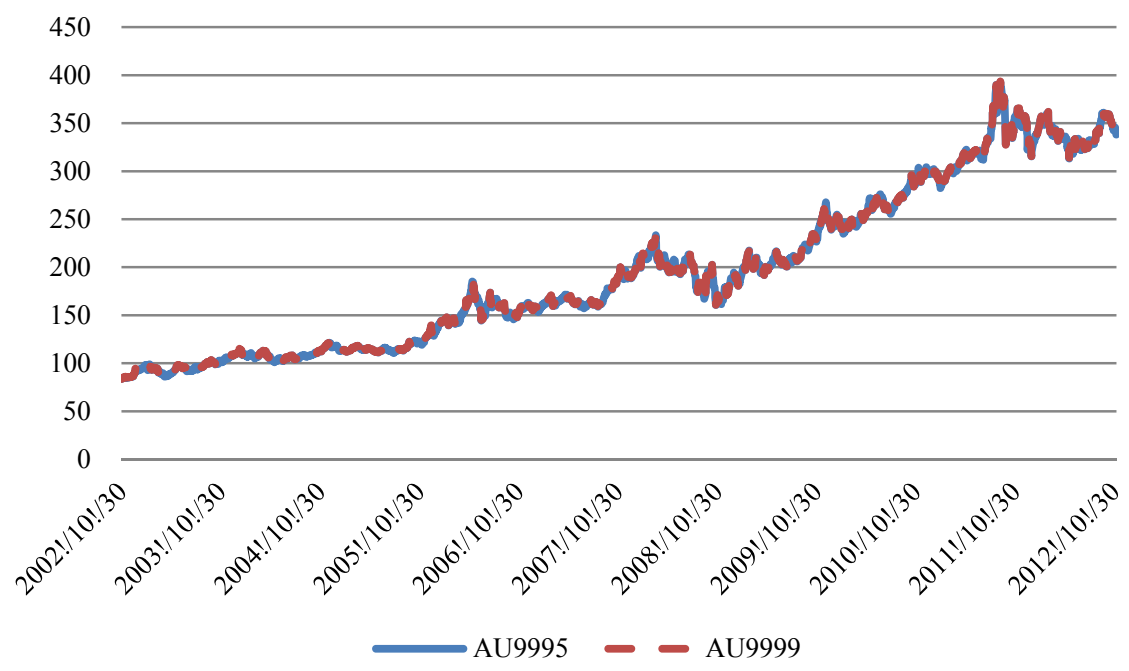

Figure 1. The movements of daily closing price in Chinese gold market

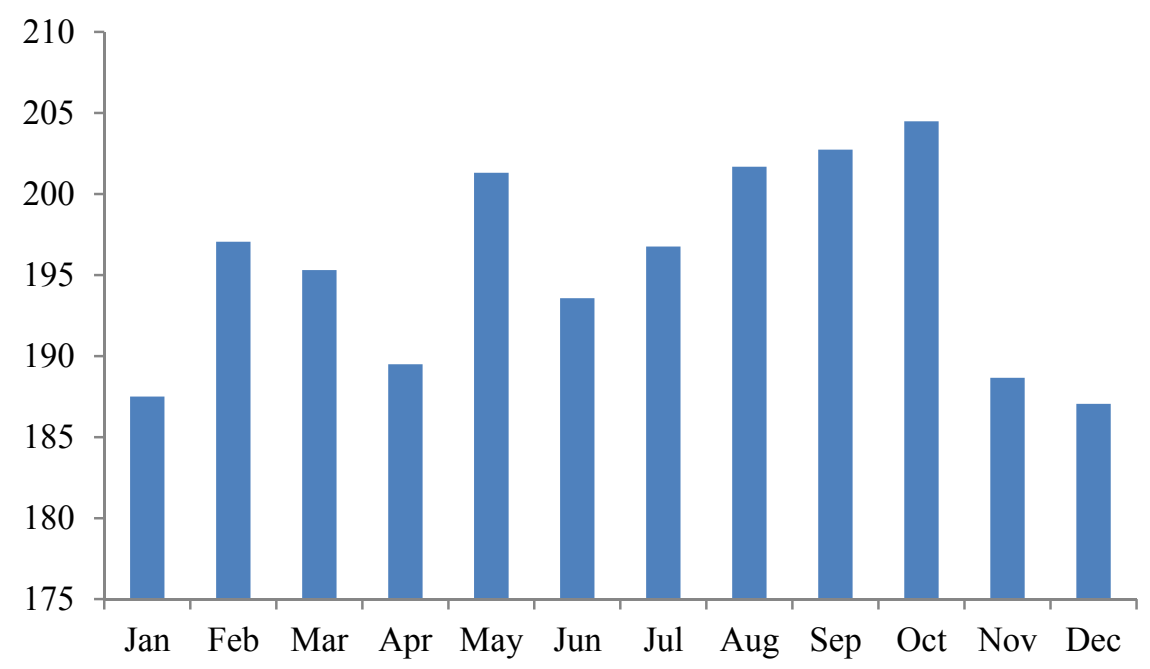

Figure 2. The average monthly price of gold (AU9999)

\section{Literature Review}

A large body of research has been devoted to the analysis of calendar anomalies and turn-of-month effects in stock returns. Odgen (1990) finds a surge in US stock returns around the turn of each calendar month and especially at the turn of the year. This result provides an explanation for the monthly effects and January effects in stock market. Using the ARCH model, Tong (1992) finds the January effect in the Taiwanese and South Korean stock market and discusses the Tax-Loss-Selling and liquidity constraint hypotheses. Mills and Coutts (1995) find the "January", "Weekend", "Half of the month" and "holiday" effects in the FT-SE 100, Mid 250 and 350 indicies. Bouman and Jacobsen (2002) study the effectiveness of "Halloween Indicator" and suggest that the market returns between November and April are significantly higher in most countries, while during the period May-October are not significantly different from zero. Keef and Roush (2005) examine the Standard \& Poor's 500 stock index and find some unique features of the day-of-the-week effects in the pre-holiday returns. In terms of the emerging markets, Bepari and Mollik (2009) find an "April effect" in Bangladesh Dhaka Stock Exchange (DSE), while the "tax-loss-selling" hypothesis is not supported. Su et al. (2011) investigate the equal-weighted and value-weighted returns of the Chinese security markets. They find that the March effect, instead of January effect, in Chinese stock market. The delay of the turn-of-the-year effect can be attributed to the national 
economical and cultural backgrounds. However, the calendar effect is also doubted by other researchers. Cheung and Coutts (1999) find no evidence of a January effect or any other monthly seasonality in the Hang Seng index. Marshall and Visaltanachoti (2010) suggest that implementing the Other January Effect (OJE) cannot bring excess risk-adjusted returns. Therefore the efficient market hypothesis cannot be rejected. Bohl and Salm (2010) also conclude that the OJE is not an international phenomenon. In terms of the commodity market, Girma and Paulson (1998) find the seasonality of petroleum future spreads and suggest that buy (sell) and hold trading strategies can be profitable. Lucey and Tully (2006) have used COMEX cash and futures data to investigated the seasonality of daily gold and silver contracts. They find a negative Monday effect in both gold and silver, across cash and futures markets. This finding also inspires us to investigate whether there exists the calendar effect in Chinese gold market. The structure of this paper is as follows. In section 2 we overview the existing literature on the concept of calendar anomalies. In section 3 we propose the methodology and the source of data. In Section 4, the results of the seasonality of gold prices are presented. Finally, we conclude the paper by summarizing the main findings.

\section{Data and Methodology}

We employ the daily closing spot prices of two primary gold products which are trading at the SGE: Au9995 and Au9999 (Note 1). Each price series runs from 30 October 2002 to 5 November 2012, providing 2425 end-of-day observations. All data is sourced from China Stock Market and Accounting Research Database (CSMAR) (Note 2). The prices are log-transformed to normalize the distributions. Following Mills and Coutts (1995), the continuously compound daily return of gold spot price $\left(R_{t}\right)$ is defined as:

$$
R_{t}=100 \times \log \left(p_{t} / p_{t-1}\right)
$$

where $p_{t}$ and $p_{t-1}$ denote the gold spot prices at time $t$ and $t-1$. Before estimating the calendar effect, we first test the stationary of both series of AU9995 and AU9999. The null hypothesis is unit root and the alternative hypothesis is level stationary. We use both ADF and Phillips-Perron (PP) including an intercept and a linear trend for the stationary test. The results are shown in Table 1. The unit root hypothesis cannot be rejected at the level for both series. But the first difference series are tested to be stationary.

Table 1. Unit root test results for both AU9995 and AU9999

\begin{tabular}{lcccccccc}
\hline & \multicolumn{3}{c}{ Level } & \multicolumn{4}{c}{ First difference } \\
& AU9995 & \multicolumn{2}{c}{ AU9999 } & \multicolumn{2}{c}{ AU9995 } & AU9999 \\
& ADF & PP & ADF & PP & ADF & PP & ADF & PP \\
\hline None & 1.84 & 1.79 & 1.85 & 1.79 & $-52.27^{* * *}$ & $-52.28^{* * *}$ & $-52.17^{* * *}$ & $-52.16^{* * *}$ \\
& $(0.98)$ & $(0.98)$ & $(0.99)$ & $(0.98)$ & $(0.0001)$ & $(0.0001)$ & $(0.0001)$ & $(0.0001)$ \\
Intercept & -0.31 & -0.33 & -0.30 & -0.34 & $-52.35^{* * *}$ & $-52.34^{* * *}$ & $-52.25^{* * *}$ & $-52.23^{* * *}$ \\
& $(0.92)$ & $(0.92)$ & $(0.92)$ & $(0.92)$ & $(0.0001)$ & $(0.0001)$ & $(0.0001)$ & $(0.0001)$ \\
Trend \& Intercept & -2.81 & -2.87 & -2.79 & -2.85 & $-52.34^{* * *}$ & $-52.34^{* * *}$ & $-52.25^{* * *}$ & $-52.23^{* * *}$ \\
& $(0.20)$ & $(0.17)$ & $(0.20)$ & $(0.18)$ & $(0.0000)$ & $(0.0000)$ & $(0.0000)$ & $(0.0001)$ \\
\hline
\end{tabular}

Ordinary Least Squares (OLS) is a commonly used method to estimate the stock market seasonality. (Cheung \& Coutts 1999; Keef \& Roush 2005) However, the daily prices of financial assets normally exhibit the heteroskedastic and clustering features. (Schwert \& Seguin 1990; Ball et al. 2006) The use of OLS leads to inconsistent parameter estimates because it assumes the constant variances (Note 3). To address this problem, Bollerslev (1986) and Taylor (1986) independently introduced the Generalized Autoregressive Conditional Heteroskedasticity (GARCH) model to allow for a time-varying conditional variance and richer dynamics. We use the following GARCH $(1,1)$ model with dummy variables to estimate the month effect in Chinese gold spot market (Note 4).

$$
\begin{gathered}
R_{t}=\sum_{i=1}^{12} b_{i} D_{i, t}+\varepsilon_{t} \quad \text { with } \varepsilon_{t} \mid \Omega_{t-1}: N\left(0, \sigma_{t}^{2}\right) \\
\sigma_{t}^{2}=\omega+\alpha \varepsilon_{t-1}^{2}+\beta \sigma_{t-1}^{2} \\
\varepsilon_{t}=z_{t} \sigma_{t} \quad \text { with } z_{t} \text { is i.i.d and } z_{t} \sim N(0,1)
\end{gathered}
$$


Where $R_{t}$ denotes the rate of gold returns. $D_{i, t}$ are the monthly dummies which indicate the month of the observation. In other words, $D_{1, t}$ takes a value of one if $t$ is in January, otherwise it is zero. $D_{2, t}$ equals to one if $t$ is in February and otherwise zero, and so on until December. We impose $\omega>0, \alpha>0$ and $\beta>0$ in order to ensure the conditional variance $\left(\sigma_{t}^{2}\right)$ is positive. If $\alpha+\beta<1$, then the process $\varepsilon_{t}$ is covariance stationary. $z_{t}$ is a series of independently and identically distributed (i.i.d.) random variables with zero mean and unit variance. We use the Generalized Error Distribution (GED), proposed by Nelson (1991), to account for the leptokurtic behavior of our daily gold returns (Note 5). The probability density function of GED distribution is then defined as:

$$
f\left(z_{t} ; v\right)=\frac{\operatorname{vexp}\left[-0.5 / z_{t} / \lambda N^{N}\right]}{\lambda 2^{(1+1 / v)} \Gamma(1 / v)}
$$

where $\lambda=\left[\left(2^{-2 / v} \Gamma(1 / v)\right) / \Gamma(3 / v)\right]^{1 / 2}, \Gamma(\cdot)$ is the Gamma function, $v$ is the thicknss-of-tail parameter (Note 6).

Before the estimation, we apply the BDS test to capture the non-linear structure in our sample. Under the null hypothesis that the series are i.i.d, the BDS statistic is asymptotically distributed as $\mathrm{N}(0,1)$. The results of BDS tests on both return series are given in Table 2. We find that all the values of BDS statistics are high enough to reject the null hypothesis at the $1 \%$ level. Both time series of daily Gold returns are non-linearly dependent. Therefore, they cannot be explained by the linear model.

Table 2. BDS test statistics

\begin{tabular}{ccccccc}
\hline \multirow{2}{*}{ Series } & $\varepsilon / \sigma$ & Value of $\varepsilon$ & 2 & \multicolumn{3}{c}{ Value of $m$} \\
\hline \multirow{4}{*}{ AU9995 } & 0.5 & 0.5847 & $7.73^{* * *}$ & $10.40^{* * *}$ & $13.18^{* * *}$ & $16.12^{* * *}$ \\
& 1.0 & 1.1695 & $9.21^{* * *}$ & $12.15^{* * *}$ & $14.70^{* * *}$ & $17.00^{* * *}$ \\
& 1.5 & 1.7542 & $9.94^{* * *}$ & $12.66^{* * *}$ & $14.74^{* * *}$ & $16.35^{* * *}$ \\
& 2.0 & 2.3389 & $9.92^{* * *}$ & $11.80^{* * *}$ & $13.33^{* * *}$ & $14.42^{* * *}$ \\
& 2.5 & 2.9236 & $9.93^{* * *}$ & $10.99^{* * *}$ & $12.02^{* * *}$ & $12.68^{* * *}$ \\
& 0.5 & 0.5789 & $7.94^{* * *}$ & $10.73^{* * *}$ & $13.57^{* * *}$ & $16.36^{* * *}$ \\
AU9999 & 1.0 & 1.1577 & $9.06^{* * *}$ & $11.88^{* * *}$ & $14.33^{* * *}$ & $16.43^{* * *}$ \\
& 1.5 & 1.7366 & $9.58^{* * *}$ & $12.22^{* * *}$ & $14.30^{* * *}$ & $15.87^{* * *}$ \\
& 2.0 & 2.3155 & $9.58^{* * *}$ & $11.32^{* * *}$ & $12.97^{* * *}$ & $14.15^{* * *}$ \\
& 2.5 & 2.8944 & $9.33^{* * *}$ & $10.28^{* * *}$ & $11.50^{* * *}$ & $12.31^{* * *}$ \\
\hline
\end{tabular}

Note: 2425 observations for each series, ${ }^{* * *}$ significant at the $1 \%$ level.

\section{Results}

Table 3 presents the results of monthly effect of daily Gold returns. We note that both return series of AU9995 and AU9999 have exhibited similar monthly effects. The average gold returns in February, September and November appear to be higher than in other months. This result is similar to the conclusion of "China Gold Report (2010)" which suggests that the strongest months for gold are January, September and November. Furthermore, the GED-GARCH $(1,1)$ estimation results are positive and statistically significant in February, April, August, September, November and December, thus providing the evidence of monthly effect in Chinese gold market. We find that the gold returns in February, April, August and November are statistically higher than in any other month. These return anomalies are closely associated with the high demand of gold products before the holidays. Most of these months with high returns occur before the public 7-day-holidays, which are also "Golden Week" in China, i.e. the Lunar New Year in January/February (Note 7), Labor's Day holiday in May and National Day holiday in October (Note 8). During these holidays, gold products, such as gold jewelries, decorations and coins, are decent gifts in Chinese traditions. Besides, the long public holidays are also popular and preferred time for young couple to hold their wedding ceremonies. All these factors contribute to the high demand of gold, especially the gold jewelries (Note 9). Furthermore, as pointed by "China Gold Report (2010)", Chinese consumers typically restock gold during the winter months. As a consequence, the investment returns of gold are pushed up by the expected strong demand in February, April, September and December. These findings provide convincing evidence of calendar anomalies. The results have implied that all strong gold prices are associated with public holidays. 
Table 3. Sample statistics and GED-GARCH $(1,1)$ test results of daily gold returns

\begin{tabular}{|c|c|c|c|c|c|c|}
\hline & \multicolumn{3}{|c|}{ AU9995 } & \multicolumn{3}{|c|}{ AU9999 } \\
\hline & Mean & Std.Dev & z-Statistic & Mean & Std.Dev & z-Statistic \\
\hline January & 0.0908 & 1.1300 & 0.1727 & 0.0961 & 1.1171 & 0.6805 \\
\hline February & 0.1355 & 1.3556 & $2.4113^{* *}$ & 0.1319 & 1.3409 & $2.1879^{* *}$ \\
\hline March & -0.0517 & 1.0530 & -0.2778 & -0.0498 & 1.0662 & -0.3412 \\
\hline April & 0.0241 & 0.9931 & $2.5974^{* * *}$ & 0.0265 & 0.9716 & $2.6862^{* * *}$ \\
\hline May & 0.0487 & 1.2909 & 0.9561 & 0.0481 & 1.2729 & 1.0870 \\
\hline June & -0.0494 & 1.1321 & -0.1537 & -0.0464 & 1.1146 & 0.0708 \\
\hline July & 0.0356 & 0.9451 & 0.1757 & 0.0329 & 0.9281 & 0.0326 \\
\hline August & 0.0885 & 1.1113 & $2.3710^{* *}$ & 0.0870 & 1.0975 & $2.4318^{* *}$ \\
\hline September & 0.1224 & 1.4786 & $3.4419^{* * *}$ & 0.1250 & 1.4700 & $3.6972^{* * *}$ \\
\hline October & 0.0023 & 1.4053 & 0.7265 & 0.0008 & 1.3965 & 0.1643 \\
\hline November & 0.2099 & 0.9573 & $3.8672^{* * *}$ & 0.2049 & 0.9165 & $3.4876^{* * *}$ \\
\hline December & 0.0542 & 1.1512 & $2.5680^{* *}$ & 0.0434 & 1.1615 & $2.1165^{* *}$ \\
\hline
\end{tabular}

Note: 2424 observations for each series, ${ }^{* *}$ significant at the $5 \%$ level, ${ }^{* * *}$ significant at the $1 \%$ level.

\section{Conclusion}

In this paper we examine the calendar effects in Chinese daily gold returns from 30 December 2002 to 05 November 2011. The daily returns of gold prices in February, April, September and December are proved to be statistically higher than in other months. The evidence of both AU9995 and AU9999 has supported this result. This phenomenon can be attributed to the "Golden Week" effects in China. The high demand before public 7-day-holidays has pushed up the gold spot prices. They might be of considerable importance for both gold investors and traders in Chinese gold market.

\section{Acknowledgement}

The authors acknowledge financial support from Science Foundation of China University of Petroleum, Beijing (No. 2462013YJRC009).

\section{References}

Ball, C. A., Torous, W. N., \& Tschoegl, A. E. (2006). The degree of price resolution: The case of the gold market. Journal of Futures Markets, 5, 29-43. http://dx.doi.org/10.1002/fut.3990050105

Batten, J. A., \& Lucey, B. M. (2009). Volatility in the gold futures market. Applied Economics Letters, 17, 187190. http://dx.doi.org/ 10.1080/13504850701719991

Bepari, M. K., \& Mollik, A. T. (2009). Seasonalities in the monthly stock returns: Evidence from Bangladesh Dhaka Stock Exchange (DSE). International Research Journal of Finance and Economics, 24, 167-176.

Bohl, M. T., \& Salm, C. A. (2010). The other January effect: International evidence. The European Journal of Finance, 16, 173-182. http://dx.doi.org/10.1080/13518470903037953

Bollerslev, T. (1986). Generalized autoregressive conditional heteroskedasticity. Journal of Econometrics, 31, 307-327. http://dx.doi.org/10.1016/0304-4076(86)90063-1

Bouman, S., \& Jacobsen, B. (2002). The Halloween indicator, "Sell in May and go away": Another puzzle. The American Economic Review, 92, 1618-1635.

Cheung, K., \& Coutts, J. A. (1999). The January effect and monthly seasonality in the Hang Seng index: 198597. Applied Economics Letters, 6, 121-123. http://dx.doi.org/10.1080/135048599353753

Fountas, S., \& Segredakis, K. N. (2002). Emerging stock markets return seasonalities: The January effect and the tax-loss selling hypothesis. Applied Financial Economics, 12, 291-299. http://dx.doi.org/ $10.1080 / 09603100010000839$

Girma, P., \& Paulson, A. (1998). Seasonality in petroleum futures spreads. The Journal of Futures Markets, 18, 581-98. http://dx.doi.org/10.1002/(SICI)1096-9934(199808)18:5<581::AID-FUT5>3.0.CO;2-1

Hansen, P. R., \& Lunde, A. (2005). A forecast comparison of volatility models: Does anything beat a GARCH (1, 1)? Journal of Applied Econometrics, 20, 873-889. http://dx.doi.org/ 10.1002/jae.800

Keef, S. P., \& Roush, M. L. (2005). Day-of-the-week effects in the pre-holiday returns of the Standard \& Poor's 500 stock index. Applied Financial Economics, 15, 107-119. http://dx.doi.org/ $10.1080 / 0960310042000293164$ 
Lucey, B. M., \& Tully, E. (2006). Seasonality, risk and return in daily COMEX gold and silver data 1982-2002. Applied Financial Economics, 16, 319-333. http://dx.doi.org/ 10.1080/09603100500386586

Lucey, B. M., \& Zhao, S. (2008). Halloween or January? Yet another puzzle. International Review of Financial Analysis, 17, 1055-1069. http://dx.doi.org/10.1016/j.irfa.2006.03.003

Marshall, B. R., \& Visaltanachoti, N. (2010). The other January effect: Evidence against market efficiency? Journal of Banking \& Finance, 34, 2413-2424. http://dx.doi.org/10.1016/j.jbankfin.2010.03.019

Mills, T. C., \& Coutts, J. A. (1995). Calendar effects in the London Stock Exchange FT-SE indices. The European Journal of Finance, 1, 79-93. http://dx.doi.org/10.1080/13518479500000010

Nelson, D. B. (1991). Conditional heteroskedasticity in asset returns: A new approach. Econometrica: Journal of the Econometric Society, 59, 347-370. http://dx.doi.org/10.2307/2938260

Ogden, J. P. (1990). Turn-of-Month evaluations of liquid profits and stock returns: A common explanation for the monthly and january effects. Journal of Finance, 45, 1259-1272. http://dx.doi.org/10.1111/j.1540-6261.1990.tb02435.x

Schwert, G. W., \& Seguin, P. J. (1990). Heteroskedasticity in stock returns. The Journal of Finance, 45, 11291155. http://dx.doi.org/10.1111/j.1540-6261.1990.tb02430.x

Su, R., Dutta, A., Xu, M., \& Ma, J. (2011). Financial anomalies: Evidence from Chinese A-share markets. International Journal of Economics and Finance, 3, 76-88. http://dx.doi.org/10.5539/ijef.v3n2p76

Taylor, S. (1986). Modelling financial time series. New York, NY: Wiley.

Tong, W. H. S. (1992). An analysis of the January effect of United States, Taiwan and South Korean stock returns. Asia Pacific Journal of Management, 9, 189-207. http://dx.doi.org/10.1007/BF01732896

World Gold Council. (2010). China gold report: Gold in the year of tiger.

\section{Notes}

Note 1. AU9995 is called "pure gold" and AU9999 is known as "thousand pure gold", which has higher purity of gold than AU9995.

Note 2. CSMAR Database is designed and developed by GTA Information Technology, which is one of major providers of China data.

Note 3. We also estimated an OLS estimation with month dummy variables, and use the ARCH (1) test to check for the absence of heteroskedasticity. The test statistics $\left(\mathrm{TR}^{2}\right)$ for series of AU9995 and AU9999 are 79.93 and 77.49 respectively. Both values are high enough to reject the null hypothesis of no conditional heteroskedasticity.

Note 4. GARCH $(1,1)$ model is appropriate to capture the volatility of a time series. (Hansen and Lunde 2005) It is also used in previous literature to investigate the seasonality and volatility structure of Gold and Silver future prices. (Lucey and Tully 2006; Batten and Lucey 2009)

Note 5. The assumption of a normal error distribution of a GARCH process is too restrictive for financial return series. In our sample, the skewness and kurtosis statistics of series AU9995 are -0.427556 and 10.20035 respectively. They are different from 0 and 3, which are the standard skewness and kurtosis values of Normal distribution. Similarly, the skewness and kurtosis statistics of series AU9999 are -0.409868 and 10.43266 respectively. Hence, we argue both series are leptokurtic and fat-tailed.

Note 6. For $v<2$, the distribution has thicker tails than the standard normal distribution.

Note 7. In our sample, six out of ten Lunar New Year Holidays occurred in February. The others occurred in late January.

Note 8. However, from 2008 the Labor's Day holiday has been reduced to three days.

Note 9. According to the WGC report (2009), jewellery contributed $78 \%$ of total gold consumption in China. It accounts for the vast majority of domestic gold demand.

\section{Copyrights}

Copyright for this article is retained by the author(s), with first publication rights granted to the journal.

This is an open-access article distributed under the terms and conditions of the Creative Commons Attribution license (http://creativecommons.org/licenses/by/3.0/). 